\title{
Identifying Key Steps for Developing Mobile Applications and Mobile Websites for Libraries
}

Devendra Dilip Potnis, Reynard RegenstreifHarms, and Edwin Cortez

\begin{abstract}
Mobile applications and mobile websites (MAMW) represent information systems that are increasingly being developed by libraries to better serve their patrons. Because of a lack of in-house IT skills and the knowledge necessary to develop MAMW, a majority of libraries are forced to rely on external IT professionals who may or may not help libraries meet patron needs but instead may deplete libraries' scarce financial resources. This paper applies a system analysis and design perspective to analyze the experience and advice shared by librarians and IT professionals engaged in developing MAMW. This paper identifies key steps and precautions to take while developing MAMW for libraries. It also advises library and information science graduate programs to equip their students with the specific skills and knowledge needed to develop and implement MAMW.
\end{abstract}

\section{INTRODUCTION}

The unprecedented adoption and ongoing use of a variety of context-specific mobile technologies by diverse patron populations, the ubiquitous nature of mobile content, and the increasing demand for location-aware library services have forced libraries to "go mobile." Mobile applications and mobile websites (MAMW), that is, web portals running on mobile devices, represent information systems that are increasingly being developed and used by libraries to better serve their patrons.

However, a majority of libraries often lack the in-house human resources necessary to develop MAMW. Because of a lack of staff equipped with the requisite IT skills and knowledge, libraries are often forced to partner with and rely on external IT professionals, potentially losing control over the process of developing MAMW. ${ }^{1}$ Partnerships with external IT professionals do not always help libraries meet the information needs of their patrons but instead can deplete their scarce financial resources. It then becomes necessary for librarians to understand the process of developing MAMW to better evaluate MAMW for better serving library patrons. One possibility

Devendra Dilip Potnis (dpotnis@utk.edu) is Associate Professor, School of Information Sciences; Reynard Regenstreif-Harms (reynardrh@gmail.com) is Project Archives Technician, Great Smoky Mountains National Park, Gatlinburg, Tennessee; and Edwin Cortez (ecortez@utk.edu) is Professor, School of Information Sciences, University of Tennessee at Knoxville. 
is to re-educate themselves through continuing education or other professional development activities. Another solution would be to see library and information science (LIS) schools strengthen their curriculum in the area of management, evaluation, and application of MAMW and related emerging technologies. Issues, challenges, and strategies for providing librarians with these opportunities are abundant and have been debated for more than thirty years, especially since libraries started experiencing the impact of microchip and portable technologies. ${ }^{2}$

Any practical and immediate guidance could help librarians in charge of developing MAMW. ${ }^{3}$ However, a majority of the practical guidance available for developing MAMW for libraries is limited to specific settings or patron populations. Also, the practical guidance is not theoretically validated, curtailing its generalizability for diverse library settings. For instance, a number of librarians and IT professionals share their experience and stories of MAMW development to serve a specific patron population in a specific library setting. ${ }^{4,5}$ Their stories typically describe their success stories of developing MAMW, the lessons learned during the development of MAMW, or their advice for developing MAMW.

This paper applies a system analysis and design perspective from the information systems discipline to examine the experience and advice shared by librarians and IT professionals for identifying the key steps and precautions to be taken when developing MAMW for libraries. System analysis and design, a branch of the information systems discipline, is the most widely used theoretical knowledgebase available for developing information systems. ${ }^{6}$ According to the system analysis and design perspective, development, planning, analysis, design, implementation, and maintenance are the six phases of building any information system. ${ }^{7}$

The next section synthesizes our method for this secondary research. The following section discusses the key steps we identified for developing, planning, analyzing, designing, implementing, and maintaining MAMW for libraries. The concluding section presents the implications of this study for libraries and LIS graduate programs.

\section{METHOD}

We began this study with a practitioner's handbook guiding libraries to use mobile technologies for delivering services to diverse patron populations. ${ }^{8}$ To search the literature relevant to our research, we devised many key phrases, including but not limited to "mobile technolog*," "mobile applications for libraries," and "mobile websites for libraries." As part of our active informationseeking process, we applied a snowball sampling technique to collect more than seventy-five scholarly research articles, handbooks, ALA library technology reports, and books hosted on EBSCO and Information Science Source databases. Our passive information-seeking was helped by article suggestions from Emerald Insight and Elsevier Science Direct, two of the most widely used journal hosting sites, in response to the journal articles we accessed there. We applied the following four criteria to establish the relevancy of publications to our research: accuracy of facts; duration of publications (i.e., from 2000 to 2014); credibility of authors; and content focused on 
problems, solutions, advice, and tips for developing MAMW. Several research articles published by Information Technology and Libraries and Library Hi Tech, two top-tier journals covering the development of MAMW for libraries, built the foundation of this secondary research.

We analyzed the collected literature using the qualitative data presentation and analysis method proposed by Miles and Huberman. ${ }^{9}$ We developed Microsoft Excel summary sheets to code the experience and advice shared by librarians and IT professionals. The coded data was read repeatedly to identify and name patterns and themes. Each relevant publication was analyzed individually and then compared across subjects to identify patterns and common categories. The inter-coder reliability between the two authors who analyzed data was 85 percent. Data analysis helped us identify the key steps needed for planning, analyzing, designing, implementing, and maintaining MAMW for libraries.

\section{FINDINGS AND DISCUSSION}

\section{Key Steps for Planning MAMW}

\section{Forming and Managing a Team}

Building teams of people with the appropriate skills, knowledge, and experience is one of the first steps suggested by the existing literature for planning MAMW. It is essential for team members to be aware of new developments and trends in the market. ${ }^{10}$ For instance, developers should be aware of print resources on relevant technologies such as Apache, ASP, JavaScript, PHP, Ruby on Rails, and Python, etc.; online resources such as detectmobilebrowser.com and W3C mobileOK Checker to test catalogs, design functionality, and accessibility on mobile devices; and various online communities of developers who could provide peer-support when needed. ${ }^{11}$ Team members are also expected to keep up with new developments in mobile devices, platforms, operating systems, digital rights management terms and conditions, and emerging standards for content formats. ${ }^{12}$ Periodic delegation of various tasks could help libraries develop MAMW effectively. ${ }^{13}$ Libraries should also form productive, financially feasible partnerships with external stakeholders such as Internet service providers and network administrators for hosting MAMW on appropriate Internet servers that meet desired safety and security standards. ${ }^{14,15}$

\section{Requirements Gathering}

Requirements for developing MAMW can be collected through empirical research and secondary research.

Typically, the goal of empirical research is to help libraries [set off as bulleted list?]gather patron preferences for and expectations of MAMW, ${ }^{16,17}$ stay abreast of the continual evolution of patron needs, ${ }^{18}$ periodically (e.g., quarterly, annually, biannually, etc.) gather and evaluate user needs, ${ }^{19}$ index the content of MAMW, ${ }^{20}$ investigate the acceptance of the library's use of MAMW by patrons, ${ }^{21}$ understand user needs, and identify top library services requested by patrons. 
Empirical research in the form of usability testing, functional validation, user surveys, etc., should be carried out before developing MAMW to inform the development process and/or after developing MAMW to study their adoption by library patrons. Empirical research typically involves the identification of patrons and other stakeholders who are going to be affected by MAMW. This step is followed by developing data-collection instruments, collecting data from patrons and other stakeholders, and analyzing qualitative and quantitative data using appropriate techniques and software. ${ }^{22}$

Secondary research mainly focuses on scanning and assessing existing literature. For instance, using appropriate datasets on mobile use, librarians may be able to identify the factors responsible for the adoption of mobile technologies. ${ }^{23}$ Typically, such factors include but are not limited to cognitive, affective, social, and economic conditions of potential users. MAMW developers could also scan the environment by examining existing MAMW and reviewing the literature to create sets of guidelines for replacing old information systems by developing new, well-functioning MAMW. ${ }^{24}$ Librarians could also scan the market for free software options to conserve financial resources. ${ }^{25}$

\section{Making Strategic Choices}

\section{Mobile Applications or Mobile Websites?}

One of the most important strategic decisions libraries need to make during this phase is whether to use a mobile app or a mobile website - that is, a web portal running on mobile devices-for offering services to patrons. Mobile websites are web browser-based applications that might direct mobile users to a different set of content pages, serve a single set of content to all patrons while using different style sheets or templates reformatted for desktop or mobile browsers, or use a site transcoder (a rule-based interpreter), which resides between a website and a web client and intercepts and reformats content in real time for a mobile device. ${ }^{26,27}$ Mobile apps are more challenging to build than mobile websites because they require separate and specific programming for each operating system. ${ }^{28}$ Mobile apps burden users and their devices. For instance, users are expected to remember the functionality of each menu item, and a significant amount of memory is required to store and support apps on mobile devices. However, potential profitability, better mobile-device functionality, and greater exposure through app stores can make mobile apps an economical option over mobile websites. ${ }^{29}$

\section{Buy or Build?}

In the planning phase, libraries also need to decide whether to buy commercial, off-the-shelf (COTS) MAMW or build a customized MAMW. MAMW need to be evaluated in terms of customer support and service, maintenance, the ability to meet patron needs, and library needs when making this choice. ${ }^{30}$ Sometimes libraries purchase COTS products and end up customizing them, benefiting from both options. For example, some libraries first purchase packaged mobile frameworks to create simple, static mobile websites and subsequently develop dynamic library apps specific to library services. ${ }^{31}$ 


\section{Managing Scope}

Many libraries have limited financial resources, which makes it necessary for their staff to manage the scope of MAMW development. The ability to prioritize tasks and identify mission-critical features of mobile MAMW are some of the most common activities undertaken by libraries to manage this scope. ${ }^{32}$ For instance, it is not practical to make entire library websites mobile because libraries would end up serving only those patrons who access their sites over mobile alone. Instead, libraries should determine which part of the website should go mobile.

A growing trend of using products like Mobile First Design to design a mobile version of a website first and then work up to a larger desktop version could help librarians better manage the scope of MAMW development. Alternatively, Jeff Wisniewski, a leading web services librarian in the United States, advises libraries to create a new mobile-optimized homepage alone, which is faster than trying to retrofit the library's existing homepage for mobile. ${ }^{33}$ This advice is highly practical because no webmaster has any interest in trying to maintain two distinct versions of the library's webpages with details such as hours of operations and contact information.

\section{Selecting the Appropriate Software Development Method}

There are three key methods for developing MAMW: structured methodologies (e.g., waterfall or parallel), rapid application prototyping (e.g., phased, prototyping, or throwaway prototyping), and agile development, an umbrella term used to refer to the collection of agile methodologies like Crystal, dynamic systems development method, extreme programming, feature-driven development, and Scrum. There is a bidirectional relationship between these MAMW development methods and the resources available for their development. Project resources such as funding, duration, and human resources influence and are affected by the type of software development method selected for developing MAMW. However, studies rarely pay attention to this important dimension of the planning phase. ${ }^{34}$

\section{Key Steps in the Analysis Phase}

\section{Requirements Analysis}

After collecting data from patrons, the next natural step is to analyze the data to inform the process of conceptualizing, building, and developing MAMW. ${ }^{35}$ The requirements-analysis phase helps libraries achieve user-centered design of MAMW and assess the return on investment in MAMW.

The context and goals of the patrons using mobile devices, and the tasks they are likely and unlikely to perform on a mobile device, are the key considerations for developing user-centered MAMW for library patrons. ${ }^{36}$ It is critical to gather, understand, and review user needs. ${ }^{37}$ Surveys can be developed on paper or online, which can be analyzed using advanced statistical techniques or qualitative software. ${ }^{38,39}$ The analysis allows the following questions to be answered: Which 
library services do patrons use most frequently on their mobile devices? What is their level of satisfaction for using those services? What types of library services and products would they like to access with their mobile phones in the future? Survey analyses can help librarians predict which mobile services patrons will find most useful; 40 they can also help librarians classify users on the basis of their perceptions, experience, and habits when using mobile technologies to access library services. ${ }^{41}$ As a result, libraries can identify and prioritize functional areas for their MAMW deployment. ${ }^{42}$ MAMW developers can learn from their users' humbling and/or frustrating experience of using mobile devices for library services. In addition, libraries can keep track of their patrons' positive and negative observations, their information-sharing practices, and howthey create group experiences on the platform provided by their libraries. ${ }^{43}$ To improve existing MAMW, libraries could also use Google Analytics, a free web metrics tool, for identifying the popularity of MAMW features and analyzing statistics on how they are used. ${ }^{44}$ To develop operating system-specific mobile apps, Google Analytics can be used to learn about the popularity of mobile devices used by patrons. ${ }^{45}$

Ideally, libraries should calculate and document ROI before investing in the development of MAMW. ${ }^{46}$ For instance, libraries can run a cost-benefit analysis on the process of developing MAMW and compare various library services offered over mobile devices. ${ }^{47}$ Typically the following data could help libraries run the cost-benefit analysis: specific deliverables (e.g., features of MAMW), resources (e.g., resources needed, available resources, etc.), risks (e.g., types of risks, level of risks, etc.), performance requirements, and security requirements for developing MAMW. This analysis would help libraries make decisions on service provisions such as specific goals to be set for developing MAMW, feasibility of introducing desired features of MAMW, and how to manage available resources to meet the set goals. ${ }^{48}$ Libraries should also examine what other libraries have already done to provide mobile services. ${ }^{49}$

\section{Communication/Liaising with Stakeholders}

The effective communication between developers and stakeholders influences almost every aspect of developing information systems. However, existing studies do not emphasize the significance of communication with stakeholders. For instance, several studies vaguely refer to the translation of user needs into technology requirements. ${ }^{50}$ But few studies point out the precise modeling technique (e.g., Entity Relationship Diagrams, Unified Modeling Language, etc.) for converting user needs into a language understood by software developers. Developers should communicate best practices and suggestions for the future implementation of MAMW in libraries, ${ }^{51}$ which involves the prediction and selection of appropriate MAMW for libraries, ${ }^{52}$ the demonstration of what is possible and how services are relevant, and how new resources can help create value for libraries. 53,54

Communication with users is also critical for creating value-added services for patrons who use different mobile technologies to meet their needs related to work, leisure, commuting, etc. ${ }^{55}$ 
However, the existing literature on MAMW development for libraries does not mention the significance of this activity.

\section{Key Steps for Designing MAMW}

\section{Prototyping}

Prototyping refers to the modeling or simulation of an actual information system. MAMW can have paper-based or computer-based prototypes. Prototyping allows developers to directly communicate with MAMW users to seek their feedback. Developers can correct or modify the original design of MAMW until users and developers are in agreement about the system design. Building consensus between MAMW developers and potential users is another key challenge to overcome during this phase, which may put a financial burden on MAMW development projects. It requires skilled personnel to manage the scope, time, human resources, and budget of such projects.

Wireframing is one of the most prominent prototyping techniques practiced by librarians and IT professionals for developing MAMW for libraries. ${ }^{56}$ This technique depicts schematic on-screen blueprints of MAMW, lacking style, color, or graphics, focusing mainly on functionality, behavior, and priority of content.

\section{Selecting Hardware, Programming Languages, Platforms, Frameworks, and Toolkits}

Existing literature on the development of MAMW for libraries covers the selection and management of software; software development kits; scripting languages like JavaScript; data management and representation languages such as HTML, XML, and their text editors; and AJAX for animations and transitions. The existing literature also guides libraries for training their staff for using MAMW to better serve patrons. ${ }^{57} \mathrm{Few}$ studies also provide guidance on selecting COTS products such as WebKit, an open source web browser engine that renders webpages on smartphones and allows users to view high-quality graphics on data networks with faster throughput. ${ }^{58}$ However, it might be a good idea to use licensed open source COTS products because licensed software allows libraries to legally distribute software within their organizations as covered by the licensing agreement. Libraries that use software-licensing agreements may also be able to seek expert help and advice whenever they have a concern or query.

In the authors' experience, librarians have shared few effective strategies to design MAMW. One key strategy is to purchase reliable device emulators and cross-compatible web editors. These technologies allow the user to work with the design at the most basic level, save documents as text, transfer the documents between web programs, and direct designers toward simple solutions. ${ }^{59}$ Sample cross-compatible web editors include, but are not limited to, Notetab Pro (http://www.notetab.com/), Code Lobster (http://www.codelobster.com/), and Bluefish (http://bluefish.openoffice.nl). 
Hybrid mobile app frameworks like Bootstrap, Ionic, Mobile Angular UI, Intel XDK, Appcelerator Titanium, Sencha, Kendo UI, and PhoneGap use a combination of web technologies like HTML, CSS, and JavaScript for developing mobile-first, responsive MAMW. A majority of these frameworks use a drag-and-drop approach and do not require any coding for developing mobile apps. One-click API connect further simplifies the process. User-interface frameworks like jQueryMobile and Topcoat eliminate the need to design user interfaces manually. Importantly, MAMW developed using such frameworks can support many mobile platforms and devices.

Toolkits like GitHub, skyronic, crudkit, and HAWHAW enable developers to quickly build mobilefriendly CRUD (create/read/update/delete) interfaces for PHP, Laravel, and Codeigniter apps. Such mobile apps also work with MySQL and other databases, allowing users to receive and process data and display information to users.

Table 1 categorizes specific hardware and software features recommended for MAMW to better serve library patrons.

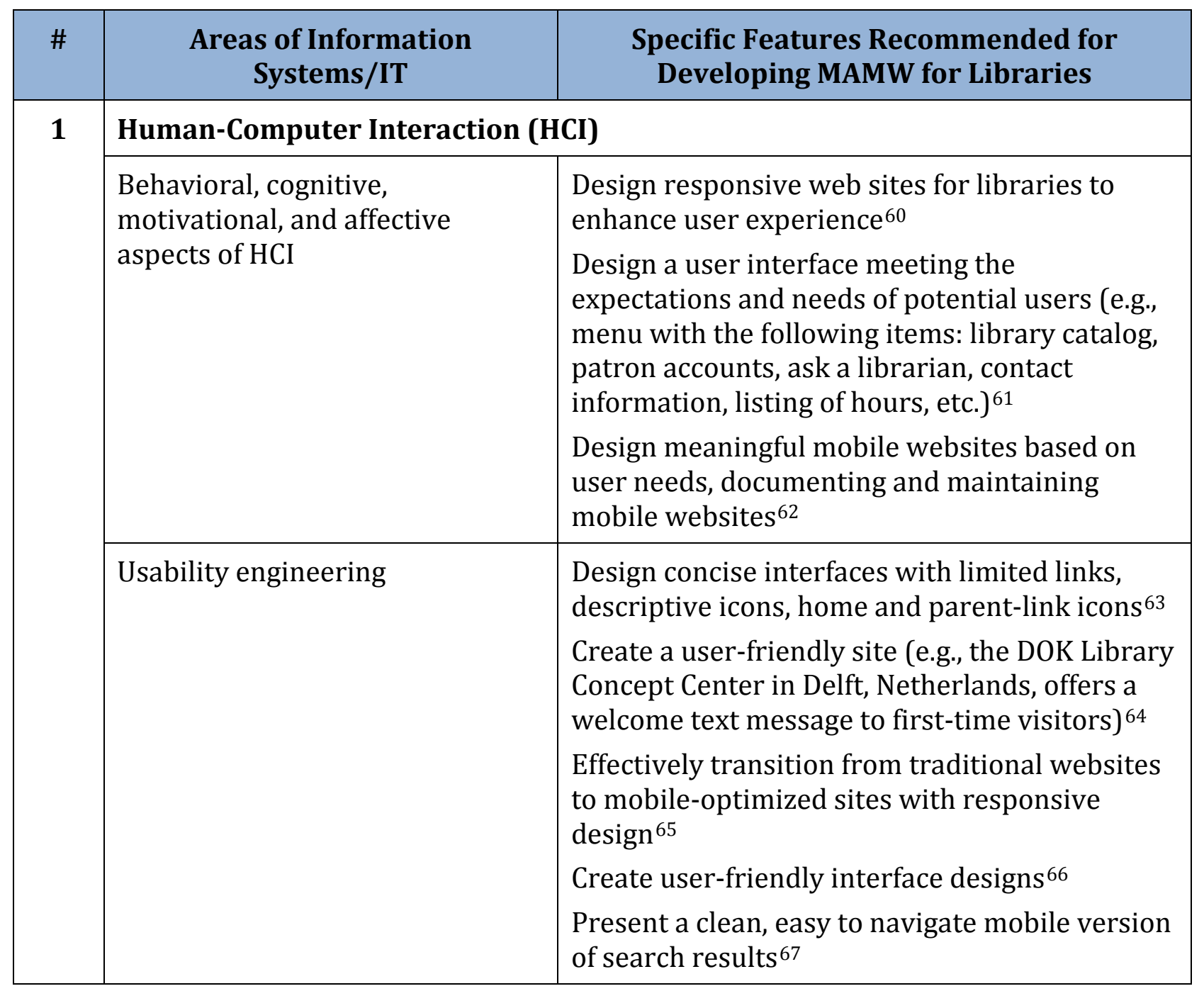




\begin{tabular}{|c|l|l|}
\hline \multirow{2}{*}{2} & Information visualization & $\begin{array}{l}\text { Automatically maintain reliable and stable } \\
\text { fundamental information required by indoor } \\
\text { localization systems }\end{array}$ \\
Save time by redesigning existing sites
\end{tabular}




\begin{tabular}{|c|c|c|}
\hline 6 & Databases & $\begin{array}{l}\text { Integrate a back-end database of metadata with } \\
\text { front-end mobile technologies } \\
\text { Integrate front-end of mobile MAMW with } \\
\text { back-end of standard databases and services }\end{array}$ \\
\hline 7 & Social Media and Analytics & $\begin{array}{l}\text { Integrate social media sites (e.g., Foursquare, } \\
\text { Facebook Place, Gowalla, etc.) with existing } \\
\text { checkout services for accurate and information } \\
\text { rich entries } \\
\text { Implement Google Voice or a free text- } \\
\text { messaging service } 87 \\
\text { Use Google Analytics for mobile optimized } \\
\text { website by copying the free JavaScript code } \\
\text { generated from Google Analytics and paste it } \\
\text { into library webpages to gain insight into what } \\
\text { resources are used and who used them } \\
\text { Integrate a geo-location feature with mobile } \\
\text { Intervices }\end{array}$ \\
\hline
\end{tabular}

Table 1. MAMW with specific hardware and software features

From the above table, which is based on the analysis of the literature on developing mobile applications and mobile websites for libraries, it becomes clear that web programming and HCI are the two leading technology areas that shape the development of MAMW and consequently the services offered by them.

\section{Designing User Interfaces of MAMW}

Librarians and IT professionals engaged in developing MAMW for libraries make the following recommendations.

Use two style sheets: CSS play a key role in offering uniform display to user interfaces for all webpages. Studies recommend designing two style sheets-namely, mobile.css and iphone.csswhen developing MAMW, since most of the time smartphones ignore mobile stylesheets. ${ }^{90}$ In that case, iphone.css could direct itself to browsers of a specific screen-width, helping those mobile devices that are not directed to the mobile website by the mobile.css stylesheet. ${ }^{91}$

Minimize use of JavaScript: JavaScript is instrumental in detecting what mobile device is being used by patrons and then directing them to the appropriate webpage with options including full website, simple text-based, and touch-mobile-optimized. However, it is critical to minimize the use of JavaScript on library mobile websites because not every smartphone offers the minimum level of support required to operate it. ${ }^{92}$

Handle images intelligently: To help patrons optimize their bandwidth use, image files on mobile sites should be incorporated with CSS rather than HTML code; also, to ensure consistency in the 
appearance of user interfaces of mobile websites, images should be kept to the same absolute size. ${ }^{93}$

\section{Key Steps for Implementing MAMW}

\section{Programming for MAMW}

Programming is at the heart of developing MAMW. As shown in table 1 above, web programming enables developers to build MAMW with a number of value-added features for patrons. For instance, a web-application server running on Cold Fusion can process data communicated via web browsers on mobile devices; this feature allows MAMW users to access search engines on library websites via smartphones. ${ }^{94}$ Also, client-side processing of classes (with a widget library) allows patrons to use their mobile devices as thin clients, thereby optimizing the use of network bandwidth. 95

\section{Testing MAMW}

Past studies recommend testing the content, display/design, and functionality of MAMW in a controlled environment (e.g., usability lab) or in the real world (i.e., in libraries).

Content: Librarians are advised to set up testing databases for testing image presentation, traditional free text search, location-based search, barcode scanning for ISBN search, QR encapsulation, and voice search. 96

Display/design: Librarians can review and test MAMW on multiple devices to confirm that everything displays and functions as intended. ${ }^{97}$ They can also test a beta version of their mobile website with varying devices to provide guidance regarding image sizing; ${ }^{98}$ beta versions are also useful in testing mobile websites for their display on different browsers and devices. ${ }^{99}$

Functionality: Librarians can set up testing practices and environments for the most heavily used device platforms (e.g., HCI incubators such as eye testing software, which is a combination of virtual emulators and mobile devices not owned by libraries). ${ }^{100,101}$ They can also use the User Agent Switcher Add-On for Firefox to test a mobile website and use web-based services like Device Anywhere and Browser Cam offering mobile emulation to test the functionality of MAMW. ${ }^{102}$

\section{Training Patrons}

Unless patrons realize the significance of a new information system for managing information resources they will hardly use it. However, training patrons for using a newly developed MAMW is almost completely missing from the studies describing the process of developing MAMW for libraries. Joe Murphy, a technology librarian at Yale University, identifies the significance of user training in managing the change from traditional to mobile search and advises librarians to explore the mobile literacy skills of their patrons and educate them on how to use new systems. ${ }^{103}$ 
MAMW cannot function properly without clean data. Cleaning up data, curating data, and addressing other data-related issues are some of the least mentioned activities in the literature for developing MAMW. However, it is necessary for librarians engaged in developing MAMW to identify and address common challenges for managing data when used for MAMW. For example, it might be a good strategy for librarians to study the best practices for managing data-related issues when offering reference services using SMS. 104

\section{Skills Needed for Maintaining MAMW}

\section{Documentation and Version Control of Software}

Past studies recommend developing a mobile strategy for building a mobile-tracking device and evaluating mobile infrastructure to ensure the continued assessment and monitoring of mobile usage and trends among patrons. ${ }^{105}$ However, past studies do not report or provide many details about the maintenance of MAMW, which leads us to infer that maintenance of MAMW involving documentation and version control is a neglected aspect of their development.

Open source software development is increasingly becoming a common practice for developing MAMW. Implementing version-control software (e.g., subversion and GitHub) to accommodate the needs of developers distributed across the world is a necessity for developing MAMW. Versioncontrol software provides a code repository with a centralized database for developers to share their code, which minimizes errors associated with overwriting or reverting code changes and maximizes software development collaboration efforts. ${ }^{106}$

\section{CONCLUSION}

There are various forces driving change in the knowledge and skills area for information professionals: technologies, changing environments, and the changing role of IT in managing and providing services to patrons. These forces affect all levels of IT-based professionals, those responsible for information processing and those responsible for information services.

This paper has examined the key steps and precautions to be taken while developing MAMW to better serve their patrons. After analyzing the existing guidance offered by librarians and IT professionals from the system analysis and design perspective, we find that some of the most ignored activities in MAMW development are selecting appropriate software development methodologies, prototyping, communicating with stakeholders, software version control, data management, and training patrons to use newly developed or revamped MAMW. The lack of attention to these activities could hinder libraries' ability to better serve patrons using MAMW. It is necessary for librarians and IT professionals to pay close attention to the above activities when developing MAMW. 
Our study also shows that web programming and HCI are the two most widely used technology areas for developing MAMW for libraries. To save their scarce financial resources, which otherwise could be invested in partnering with external IT professionals, libraries could either train their existing staff or recruit LIS graduates equipped with the skills and knowledge identified in this paper to develop MAMW (see table 2).

\begin{tabular}{|c|c|c|}
\hline$\#$ & Key Steps for Developing MAMW & $\begin{array}{l}\text { Skills and Knowledge Required } \\
\text { for Developing MAMW }\end{array}$ \\
\hline A & Planning Phase & \\
\hline 1 & Forming and managing team & Human resource management \\
\hline 2 & Making strategic choices & $\begin{array}{l}\text { Time management } \\
\text { Cost management } \\
\text { Quality management } \\
\text { Human resource management } \\
\text { (e.g., staff capacity) }\end{array}$ \\
\hline 3 & Requirements gathering & $\begin{array}{l}\text { Research (empirical and } \\
\text { secondary) }\end{array}$ \\
\hline 4 & $\begin{array}{l}\text { Managing scope (e.g., managing financial } \\
\text { resources, prioritizing tasks, identifying } \\
\text { mission-critical features of MAMW, etc.) }\end{array}$ & Scope management \\
\hline 5 & $\begin{array}{l}\text { Selecting an appropriate software } \\
\text { development method }\end{array}$ & $\begin{array}{l}\text { Time management } \\
\text { Cost management } \\
\text { Quality management }\end{array}$ \\
\hline B & Analysis Phase & \\
\hline 6 & Requirements analysis & $\begin{array}{l}\text { Research (empirical and } \\
\text { secondary) }\end{array}$ \\
\hline 7 & Communication/liaising with stakeholders & Communications management \\
\hline C & Design Phase & \\
\hline 8 & Prototyping & Software development (HCI) \\
\hline 9 & $\begin{array}{l}\text { Selecting hardware and programming } \\
\text { languages and platforms }\end{array}$ & $\begin{array}{l}\text { Software development (web } \\
\text { programming and } \mathrm{HCI} \text { ) }\end{array}$ \\
\hline 10 & Designing user interfaces of MAMW & Software development (HCI) \\
\hline D & Implementation Phase & \\
\hline 11 & Programming for MAMW & $\begin{array}{l}\text { Software development (web } \\
\text { programming-e.g., Android, iOS, } \\
\text { Visual C++, Visual C\#, Visual Basic, } \\
\text { etc.) }\end{array}$ \\
\hline 12 & Testing MAMW & $\begin{array}{l}\text { Software development (web } \\
\text { programming and } \mathrm{HCI} \text { ) }\end{array}$ \\
\hline
\end{tabular}




\begin{tabular}{|c|c|c|}
\hline 13 & Training patrons & Human resource management \\
\hline 14 & $\begin{array}{l}\text { Data management (e.g., cleaning up data, } \\
\text { curating data, etc.) }\end{array}$ & Data management \\
\hline $\mathbf{E}$ & Maintenance Phase & \\
\hline 15 & $\begin{array}{l}\text { Documentation and version control of } \\
\text { software }\end{array}$ & $\begin{array}{l}\text { Software development (web } \\
\text { programming and } \mathrm{HCI} \text { ) }\end{array}$ \\
\hline
\end{tabular}

Table 2. Skills and knowledge necessary to develop MAMW

The management of scope, time, cost, quality, human resources, and communication related to any project is known as project management. ${ }^{107}$ In addition to the skills and knowledge related to project management, librarians would also need to be proficient in software development (with an emphasis on HCI and web programming), data management, and the proper methods for conducting empirical and secondary research for developing MAMW.

If LIS programs equip their graduate students with the skills and knowledge identified in this paper, the next generation of LIS graduates could develop MAMW for libraries without relying on external IT professionals, which would make libraries more self-reliant and better able to manage their financial resources. ${ }^{108}$

This paper assumes a very small number of scholarly publications to be reflective of the realworld scenarios of developing MAMW for all types of libraries. This assumption is one of the limitations of this study. Also, the sample of publications analyzed in this study is not statistically representative of the development of MAMW for libraries around the world. In the future, the authors plan to interview librarians and IT professionals engaged in developing and maintaining MAMW for their libraries to better understand the landscape of developing MAMW for libraries.

\section{REFERENCES}

1. Devendra Potnis, Ed Cortez, and Suzie Allard, "Educating LIS Students as Mobile Technology Consultants" (poster presented at 2015 Association for Library and Information Science Education Annual Meeting, Chicago, January 25-27), http://f1000.com/posters/browse/summary/1097683.

2. Edwin Michael Cortez, "New and Emerging Technologies for Information Delivery," Catholic Library World no. 54 (1982): 214-18.

3. Kimberly D. Pendell and Michael S. Bowman, "Usability Study of a Library's Mobile Website: An Example from Portland State University," Information Technology \& Libraries 31, no. 2 (2012): 45-62, http://dx.doi.org/10.6017/ital.v31i2.1913.

4. Godmar Back and Annette Bailey, "Web Services and Widgets for Library Information Systems," Information Technology \& Libraries 29 no. 2 (2010): 76-86, http://dx.doi.org/10.6017/ital.v29i2.3146. 
5. Hannah Gascho Rempel and Laurie Bridges, "That was Then, This is Now: Replacing the Mobile Optimized Site with Responsive Design," Information Technology \& Libraries 32, no. 4 (2013): 8-24, http://dx.doi.org/10.6017/ital.v32i4.4636.

6. June Jamrich Parsons and Dan Oja, New Perspectives on Computer Concepts 2014: Comprehensive, Course Technology (Boston: Cengage Learning, 2013).

7. Ibid.

8. Andrew Walsh, Using Mobile Technology to Deliver Library Services: A Handbook (London: Facet, 2012).

9. Matthew B. Miles and A. Michael Huberman, Qualitative Data Analysis (Thousand Oaks, CA: Sage, 1994).

10. Bohyun Kim, “Responsive Web Design, Discoverability and Mobile Challenge," Library Technology Reports 49, no 6 (2013): 29-39, https://journals.ala.org/ltr/article/view/4507.

11. James Elder, "How to Become the "Tech Guy and Make iPhone Apps for Your Library," The Reference Librarian 53, no. 4 (2012): 448-55, http://dx.doi.org/10.1080/02763877.2012.707465.

12. Sarah Houghton, "Mobile Services for Broke Libraries: 10 Steps to Mobile Success,” The Reference Librarian 53, No. 3 (2012): 313-21, http://dx.doi.org/10.1080/02763877.2012.679195.

13. Pendell and Bowman, "Usability Study."

14. Lisa Carlucci Thomas, "Libraries, Librarians and Mobile Services," Bulletin of the American Society for Information Science \& Technology 38, no. 1 (2011): 8-9, http://dx.doi.org/10.1002/bult.2011.1720380105.

15. Elder, "How to Become the "Tech Guy."”

16. Kim, "Responsive Web Design."

17. Chad Mairn, "Three Things You Can Do Today to Get Your Library Ready for the Mobile Experience," The Reference Librarian 53, no. 3 (2012): 263-69, http://dx.doi.org/10.1080/02763877.2012.678245.

18. Rempel and Bridges, "That was Then."

19. Rachael Hu and Alison Meier, "Planning for a Mobile Future: A User Research Case Study From the California Digital Library," Serials 24, no. 3 (2011): S17-25.

20. Kim, "Responsive Web Design." 
21. Lorraine Paterson and Boon Low, "Student Attitudes Towards Mobile Library Services for Smartphones," Library Hi Tech 29, no. 3 (2011): 412-23, http://dx.doi.org/10.1108/07378831111174387.

22. Jim Hahn, Michael Twidale, Alejandro Gutierrez and Reza Farivar, "Methods for Applied Mobile Digital Library Research: A Framework for Extensible Wayfinding Systems," The Reference Librarian 52, no. 1-2 (2011): 106-16, http://dx.doi.org/10.1080/02763877.2011.527600.

23. Patterson and Low, "Student Attitudes."

24. Gillian Nowlan, "Going Mobile: Creating a Mobile Presence for Your Library," New Library World 114, no. 3/4 (2013): 142-50, http://dx.doi.org/10.1108/03074801311304050.

25. Elder, "How to Become the "Tech Guy."

26. Matthew Connolly, Tony Cosgrave, and Baseema B. Krkoska, “Mobilizing the Library's Web Presence and Services: A Student-Library Collaboration to Create the Library's Mobile Site and iPhone Application," The Reference Librarian 52, no. 1-2 (2010): 27-35, http://dx.doi.org/10.1080/02763877.2011.520109.

27. Stephan Spitzer, "Make That to Go: Re-Engineering a Web Portal for Mobile Access," Computers in Libraries 3 no. 5 (2012): 10-14.

28. Houghton, "Mobile Services."

29. Cody W. Hanson, "Mobile Solutions for Your Library," Library Technology Reports 47, no. 2 (2011): 24-31, https://journals.ala.org/ltr/article/view/4475/5222.

30. Terence K. Huwe, “Using Apps to Extend the Library’s Brand,” Computers in Libraries 33, no. 2 (2013): 27-29.

31. Edward Iglesias and Wittawat Meesangnill, "Mobile Website Development: From Site to App," Bulletin of the American Society for Information Science and Technology 38, no. 1 (2011): 1823.

32. Jeff Wisniewski, "Mobile Usability," Bulletin of the American Society for Information Science \& Technology 38, no. 1 (2011): 30-32, http://dx.doi.org/10.1002/bult.2011.1720380108.

33. Jeff Wisniewski, “Mobile Websites with Minimal Effort," Online 34, no. 1 (2010): 54-57.

34. Hahn et al., "Methods for Applied Mobile Digital Library Research."

35. J. Michael DeMars, "Smarter Phones: Creating a Pocket Sized Academic Library," The Reference Librarian 53, no. 3 (2012): 253-62, http://dx.doi.org/10.1080/02763877.2012.678236. 
36. Kim Griggs, Laurie M. Bridges, and Hannah Gascho Rempel, "Library/Mobile: Tips on Designing and Developing Mobile Websites," Code4lib no. 8 (2009), http://journal.code4lib.org/articles/2055.

37. DeMars, "Smarter Phones."

38. Hahn et al., "Methods for Applied Mobile Digital Library Research."

39. Beth Stahr, "Text Message Reference Service: Five Years Later," The Reference Librarian no. 52, no. 1-2 (2011): 9-19, http://dx.doi.org/10.1080/02763877.2011.524502.

40. Patterson and Low, "Student Attitudes."

41. Ibid.

42. Ibid.

43. Hanson, "Mobile Solutions for Your Library."

44. Stahr, "Text Message Reference Service."

45. Spitzer, "Make That to Go."

46. Allison Bolorizadeh et al., “Making Instruction Mobile,” The Reference Librarian 53, no. 4 (2012): 373-83, http://dx.doi.org/10.1080/02763877.2012.707488.

47. Maura Keating, "Will They Come? Get Out the Word About Going Mobile," The Reference Librarian no. 52, no. 1-2 (2010): 20-26, http://dx.doi.org/10.1080/02763877.2010.520111.

48. Patterson and Low, "Student Attitudes."

49. Hanson, "Mobile Solutions for Your Library."

50. Patterson and Low, "Student Attitudes."

51. Hanson, "Mobile Solutions for Your Library."

52. Cody W. Hanson, "Why Worry About Mobile?," Library Technology Reports no. 47, no. 2 (2011): 5-10, https://journals.ala.org/ltr/article/view/4476.

53. Keating, "Will They Come?"

54. Spitzer, "Make That to Go."

55. Kim, "Responsive Web Design."

56. Wisniewski, "Mobile Usability."

57. Elder, "How to Become the 'Tech Guy."' 
58. Sally Wilson and Graham McCarthy, "The Mobile University: From the Library to the Campus," Reference Services Review 38, no. 2 (2010): 214-32, http://dx.doi.org/10.1108/00907321011044990.

59. Brendan Ryan, "Developing Library Websites Optimized for Mobile Devices," The Reference Librarian 52, no. 1-2 (2010): 128-35, http://dx.doi.org/10.1080/02763877.2011.527792.

60. Kim, "Responsive Web Design."

61. Connolly, Cosgrave, and Krkoska, "Mobilizing the Library’s Web presence and Services.”

62. DeMars, "Smarter Phones."

63. Mark Andy West, Arthur W. Hafner, and Bradley D. Faust, "Expanding Access to Library Collections and Services Using Small-Screen Devices," Information Technology \& Libraries 25 (2006): 103-7.

64. Houghton, "Mobile Services."

65. Rempel and Bridges, "That was Then."

66. Elder, "How to Become the 'Tech Guy."”

67. Heather Williams and Anne Peters, “And That's How I Connect to MY Library: How a 42Second Promotional Video Helped to launch the UTSA Libraries' New Summon Mobile Application," The Reference Librarian 53, no. 3 (2012): 322-25, http://dx.doi.org/10.1080/02763877.2012.679845.

68. Hahn et al., "Methods for Applied Mobile Digital Library Research."

69. Danielle Andre Becker, Ingrid Bonadie-Joseph, and Jonathan Cain, "Developing and Completing a Library Mobile Technology Survey to Create a User-Centered Mobile Presence," Library Hi-Tech 31, no. 4 (2013): 688-99, http://dx.doi.org/10.1108/LHT-03-2013-0032.

70. Rempel and Bridges, “That was Then.”

71. Iglesias and Meesangnill, "Mobile Website Development."

72. Elder, "How to Become the 'Tech Guy."'

73. Andrew Walsh, "Mobile Information Literacy: A Preliminary Outline of Information Behavior in a Mobile Environment," Journal of Information Literacy 6, no. 2 (2012): 56-69, http://dx.doi.org/10.11645/6.2.1696.

74. Back and Bailey, "Web Services and Widgets."

75. Ibid.

76. Ibid.

77. Spitzer, "Make That to Go." 
78. Iglesias and Meesangnill, "Mobile Website Development."

79. Bohyun Kim, "The Present and Future of the Library Mobile Experience," Library Technology Reports 49, no. 6 (2013): 15-28, https://journals.ala.org/ltr/article/view/4506.

80. Pendell and Bowman, "Usability Study."

81. Hahn et al., "Methods for Applied Mobile Digital Library Research."

82. Andromeda Yelton, "Where to Go Next," Library Technology Reports 48, no. 1 (2012): 25-34, https://journals.ala.org/ltr/article/view/4655/5511.

83. Ibid.

84. Hahn et al., "Methods for Applied Mobile Digital Library Research."

85. Houghton, "Mobile Services."

86. Ibid.

87. Mairn, "Three Things You Can Do Today."

88. Ibid.

89. Tamara Pianos, "EconBiz to Go: Mobile Search Options for Business and EconomicsDeveloping a Library App for Researchers," Library Hi Tech 30, no. 3 (2012): 436-48, http://dx.doi.org/10.1108/07378831211266582.

90. DeMars, "Smarter Phones."

91. Ryan, "Developing Library Websites."

92. Pendell and Bowman, "Usability Study."

93. Ryan, "Developing Library Websites."

94. Michael J. Whitchurch, "QR Codes and Library Engagement," Bulletin of the American Society for Information Science \& Technology 38, no. 1 (2011): 14-17.

95. Back and Bailey, "Web Services and Widgets."

96. Jingru Hoivik, “Global Village: Mobile Access to Library Resources,” Library Hi Tech 31, no. 3 (2013): 467-77, http://dx.doi.org/10.1108/LHT-12-2012-0132.

97. Elder, "How to Become the 'Tech Guy."'

98. Ryan, "Developing Library Websites."

99. West, Hafner and Faust, "Expanding Access."

100. Hu and Meier, "Planning for a Mobile Future."

101. Iglesias and Meesangnill, "Mobile Website Development." 
102. Wisniewski, "Mobile Usability.”

103. Joe Murphy, “Using Mobile Devices for Research: Smartphones, Databases and Libraries,” Online 34, no. 3 (2010): 14-18.

104. Amy Vecchione and Margie Ruppel, "Reference is Neither Here nor There: A Snapshot of SMS Reference Services," The Reference Librarian 53, no. 4 (2012): 355-72, http://dx.doi.org/10.1080/02763877.2012.704569.

105. Hu and Meier, "Planning for a Mobile Future."

106. Wilson and McCarthy, "The Mobile University."

107. Project Management Institute, A Guide to the Project Management Body of Knowledge (PMBOK Guide) (Newtown Square, PA: Project Management Institute, 2013).

108. Devendra Potnis et al., "Skills and Knowledge Needed to Serve as Mobile Technology Consultants in Information Organizations," Journal of Education for Library \& Information Science 57 (2016): 187-96. 